\title{
Empowerment: The Teacher Training Model in Primary and Secondary Schools-A Case Study of Singapore
}

\author{
Xianwei Xia \\ Zhejiang Radio \& TV University, Hangzhou, China \\ Email: xiaxianwei1989@163.com
}

How to cite this paper: Xia, X.W. (2020) Empowerment: The Teacher Training Model in Primary and Secondary Schools-A Case Study of Singapore. Open Access Library Journal, 7: e6329.

https://doi.org/10.4236/oalib.1106329

Received: April 16, 2020

Accepted: April 27, 2020

Published: April 30, 2020

Copyright $\odot 2020$ by author(s) and Open Access Library Inc.

This work is licensed under the Creative Commons Attribution International License (CC BY 4.0).

http://creativecommons.org/licenses/by/4.0/

\begin{abstract}
Singapore's education has trained numerous high-quality talents for the country's economic development, and the teacher education policy and model play a significant role in the entire education system. From the view of the empowerment theory, Singapore's teacher training policy has a clear orientation and systematic contents. Besides, Singapore has established a state-dominated and decentralized teacher training system, and it has also formed a teacher training alliance to promote the shaping of teacher training culture. What's more, it has constructed diversified and individualized curriculum resources, platforms and the systematic "training-promotion" performance feedback system etc.. All of these form the teacher training model that is in the line with Singapore's national conditions, which sheds lights on the teacher training reform of primary and secondary schools in China.
\end{abstract}

\section{Subject Areas}

Education

\section{Keywords}

Teacher Training, Primary and Secondary Schools, Empowerment, Singapore

\section{Introduction}

In the era of globalization and information, the world is changing rapidly, causing an intensifying competition among various countries. Under such a global situation, China's development, in particular, has entered a new era where the quality of talents is critical to China's social and economic development and the great rejuvenation of the Chinese nation. Therefore, teacher education is of in- 
creasing significance in order to cultivate high-quality nationals, and the improvement of teachers' quality has become one of the most important aspects of education reforms in major countries, including China. Looking around Asian countries, Singapore, as one of the "Newly Industrial Economies", ranks in the top three in the world competitiveness and global competitiveness indicators, which is obviously better than China. The rise of Singapore is directly related to the high-quality nationals cultivated by the outstanding education level, and so Singapore's teacher training model is worth exploring and learning.

\section{Logic Analyses on Teacher Training under the Empowerment}

Since the 1960s, the empowerment theory has been applied in larger scopes from the initial social work to the economic and educational development filed, and its connotation has also been expanding over the last 50-year development. According to the American scholar Rappaport, the father of empowerment, the concept of empowerment refers to "a constant and conscious process in which individuals can master their own lives as much as possible, and through certain processes people who lack equal sharing of resources can gain or control resources more easily" (Bret Kloos, et al., 2015) [1]. This theory consists of two aspects: the empowerment and ability enhancement. The empowerment refers to promoting the development of people or things with the help of external forces; and the ability enhancement refers to promoting the initiative of individuals to enhance their advantages and developmental abilities. This paper applies this concept to teacher training and professional development, discusses the empowerment of teacher training, and eventually presents the empowerment pattern of teacher training in Chinese primary and secondary schools by analyzing and drawing lessons from the "empowerment" and "ability enhancement" measures taken by Singapore.

Based on the core value of the empowerment theory, the empowerment discussed in this paper mainly includes the following aspects: policy empowerment, system empowerment and environment empowerment. Policy empowerment focuses on the positioning and planning of teacher training; System empowerment lies in the establishment of a teacher training system in line with national realities and the needs of teacher development and the construction of an ecological mechanism that integrates between the professional development and career promotion of teachers; environmental empowerment lies in shaping the conceptual cognition of teacher training and professional development and forming the cultural atmosphere and environment of teachers' participating consciousness. In terms of the ability enhancement, it consists of external and internal enhancement. Internal enhancement emphasizes the integration of teachers' training resources of primary and secondary schools, including the optimization of faculty and curriculum resources. However, external enhancement emphasizes external promotion of teacher training, concentrating on the impor- 
tance of driving forces like the quality standard system and the assessment system to teacher training.

\section{The Empowerment Model of Teacher Training in Singapore}

\subsection{Policy Empowerment: Teacher Training Policies with the Clear Orientation and Systematic Contents}

Teacher is the key to the success of education. Different teachers have different professional ideals, and thus in order to better develop the professional potential of each teacher and ensure their access to training Singapore has promulgated policies to support teachers' off-the-job training and to implement teachers' professional development, and the government has constantly improved relevant policies since the end of 1990s. Singapore has established the teacher training policy system with clear orientation and systematic contents over the last two decades.

In 1998, the Ministry of Education of Singapore implemented the Professional Development Leave (PDL) and set up the President's Award for Teachers. PDL stipulates that teachers in primary and secondary schools must receive at least 100-hour training every year. Teachers can choose the training in the form of off-the-job or on-the-job according to their needs, or receive training at home or abroad (Zhu Huaixin \& Liu Xiaonan, 2004) [2]. One selecting standard of the President's Award for Teachers is that candidates should "set the example of continuous learning". This award aims to encourage teachers to establish the idea and awareness of professional development and internalize the training policy to teachers spirits by the policy enforcement and the setting of national awards. In 2001, in order to better improve the enthusiasm and initiative of teachers' participating in training and learning, Singapore implemented the Education Service Professional Development and Career Plan which provides teachers with three choices, namely teaching track, leadership track, and senior specialist track, and each requires related training programs. In 2006, GROW package 2.0 was implemented to encourage teachers to take training by paying further education and providing scholarships to assisting professional development. It is showed that the clear orientation and systematic content of teacher training in Singapore facilitate teachers professional development and promotion.

\subsection{System Empowerment: The State-Dominated and Decentralized Training System}

The efficient and smooth operation system is an important factor ensuring teacher training. The system empowerment is to build a clear boundary between rights and duties and a linking mechanism and to impel multiple interest bodies to support and participate in teacher training, which is the important guarantee of sustainable development of teacher training and teacher profession. The Min- 
istry of Education of Singapore, as the management institution, has managed teachers in direct, guided the teacher training, and it has established a state-dominated and decentralized training system.

Since the declaration of autonomy in 1959, Singapore's educational development has gone through three stages: survival-oriented education (1959-1978), efficiency-oriented education (1979-1996), and competence-oriented education (1997-now). During these stages the Teachers' Training College (TTC) has gradually transformed into the National Institute of Education (NIE). Generally speaking, the courses offered by the NIE pay more attention to the growth of disciplines and professional knowledge, and provide higher degrees that teachers pursues. However, there are many ways to carry out the on-the-job teacher training such as introducing new approach-project-based learning or information-teaching-integrated methods. Most of the professional development is school-based, guided by developers who are familiar with school issues. Each school sets up funds to help the professional development of teachers. Therefore, Singapore has established a decentralized teacher training system dominated by the NIE in the education development, that is the educational background promotion is led by the country and the short-term training is led by schools.

\subsection{Environment Empowerment: Creating the Teacher Training Alliance and Training Culture}

The National Institute of Education of Singapore put forward a teacher education guidance for the $21^{\text {st }}$ century in 2009 and formed the teacher training alliance associating with the Ministry of Education and schools in order to cope with the educational challenges and future needs brought by globalization and to improve the quality of teachers. The guidance proposed new values, skills, the knowledge framework (V3SK model) and the Graduand Teacher Competencies Framework (GTCF). It emphasized the refinement of teacher training and encouraged candidates to take an additional two-year course for a master's degree after completing the postgraduate education courses. In addition, after completing the bachelor's program, the top $10 \%$ candidates are encouraged to take another one-year program to obtain a master's degree [3].

Ideas in the teacher education guidance are still leading in Singapore teacher education. Singapore's Ministry of Education issued an implementation report in 2012, restating the ideas in the guidance and some further practices, for example, it should strengthen the cooperation between the Ministry of Education and school, the close combination between teaching contents and methods and the connection between theory and practice; it should apply the Assessment Competency Framework (ACF) to education, curriculum, and discipline researches and develop the Assessment Literacy Framework on the base of ACF [4]. As a result, advanced ideas of teacher training together with the establishment of teacher education alliance create a strong cultural atmosphere for teacher training where teachers' participating in training becomes a consensus and conscious behavior. 


\subsection{Internal Enhancement: Establishing Diversified and Individualized Curriculum Resources and Platforms}

Curriculum is at the micro level in the whole system of empowerment and ability enhancement, and it is also the core of teacher training. For the internal enhancement of teacher training, the most important part lies in the construction and optimization of the curriculum system. As the central part of reflecting the ideas and achievements of teacher training, the effectiveness of curriculum system plays a key role in the development of teacher training. The Singapore government emphasizes a lifelong learning. In addition to the initial teacher education, the NIE also provides professional development training for on-the-job teachers and school leaders with diversified and individualized curriculum to meet their needs which mainly include higher degree courses, leadership development courses, professional development courses and symposium activities.

Higher degree courses provide high-quality and rigorous courses challenging teachers' thoughts so as to improve teachers' skills and expand their career prospects. Leadership development courses are designed to meet the needs and challenges of the rapidly changing education system and to cultivate different education leaders. There are relevant courses and training schedules: education leadership programme (6 months), leader for leaders programme (3 weeks), school management and leadership course (17 weeks), senior teacher programme (4 weeks). Professional development activities and courses are regarded as teachers' continuing education and also as a part of teachers' lifelong learning. They are designed and developed jointly by the NIE and the Ministry of Education. More than 500 kinds of courses are offered every year for teachers to choose according to their own specialties, and these courses can improve their professional knowledge and enhance their teaching wisdom to deal with teaching challenges more efficiently. Symposium activities are mainly provided by the Ministry of Education of Singapore, the NIE, the Education Research Association Singapore (ERAS), and schools at all levels. The activities include professional development courses, workshops, seminars, forums, etc., which intent to enhance teachers' subject knowledge and teaching ability, and to share the latest trend of teaching materials, methods and courses by holding seminars [5].

\subsection{External Enhancement: Establishing the Systematic "Training-Promotion" Performance Feedback System}

The external enhancement stresses the promoting effect of external forces in the process of ability enhancement. It advocates to activate the subject through external forces, and to achieve the purpose of continuous enhancement through the continuous circulation and construction of the interaction between object and subject (Fan Bin, 2004) [6]. In Singapore if teachers want to make continuous progresses in careers, they must pass a strict performance assessment process, which is not only the premise of the promotion system, but also a vital guarantee for improving the teachers' quality and the healthy development of 
teachers' specialization. The teacher assessment and feedback has a positive influence on both teachers themselves and teaching works, for it can increase teachers' satisfaction with their work, provide a protection for their work to some extent, and promote the professional growth.

The Singapore government fully implemented the performance management system in 2005 and all promotions need to be evaluated and assessed. After three-year teaching, teachers in Singapore will be evaluated every year and rethink their career tracks to see if they are suitable for teaching, curriculum researches or school leadership or not. Along with the promotion in each track, the salary also increases. Teachers who are suitable for leadership will be included in the middle level management team, get trained, be assigned a new role, and then be assessed to serve as vice principal or as principal in the future. Teachers need to participate in the corresponding training and practices to pass each assessment thus reaching a new stage of their career. So, for teachers who want to be promoted they have continued to receive professional education and training in order to gain orderly promotion in accordance with the professional development path set by the Ministry of Education of Singapore.

\section{The Dilemma of Teacher Training in Primary and Secondary Schools in China under the Empowerment}

\subsection{Policy Empowerment: Lagging Teacher Training Policies Hindering the Transformation and Development of Education}

The policy making is often on the base of solving the real dilemma, and it is a process of value choices based on the judgment of the dilemma. Policies should be revised and improved with the emergence and change of new situations and new problems. When we reviewed the evolution of teacher training policy in primary and secondary schools in China, from the academic compensation in the first place to the "post education" period of professional development, the policy essence in each stage changes with the transformation of historical stages. But in general, it has shown that the evolution process of policy is from scattered to systematic, from partial to comprehensive, from shallow to deep, from experience-based to professional, and from setting requirements to establishing standards. The specialization, institutionalization, systematization, scientization and individualization of policy are becoming more and more obvious (Li Jinyu \& Shi Junlong, 2012) [7].

However, there are many problems in teacher training restricting and affecting the development of teacher training. The reasons can be described as follow. The history of the development of teacher training in primary and secondary schools in China is short. And the educational reform is lagging behind the transformation and development of China's economy and society. Besides, the culture and idea of teachers' professional development consciousness have not been formed yet. In addition, there is no close relationship between teachers' professional development and promotion in essence. The planned training sys- 
tem dominated by the state being unable to meet the needs of market-oriented and individualized teachers' development is another reason. The problems are the lagging of the policy itself, rather than the implementation process. As a result, it is necessary to re-examine the existing teacher training policies, to construct a new and advanced teacher training idea from the source, and to reshape the cultural consciousness of teacher training. Based on this, the first thing to be solved in terms of the policy empowerment is the dilemma of the lagging orientation of teacher training and to revise and improve the teacher training policy of primary and secondary schools from a long-term perspective.

\subsection{System Empowerment: The Rigid Teacher Training System Constraining the Transformation and Development of Education}

The efficient and smooth operation system is an important factor to ensure the development of teacher training. The system empowerment is to form a clear boundary between rights and duties and to promote the participation of multiple interest bodies, which is the important guarantee for the sustainable development of teacher training. System empowerment can be divided into plan-oriented, market-oriented and service-oriented according to the orientation of teacher training system. The development of teacher training system in primary and secondary schools in China has experienced three stages: the absolute dominance of planned system, the market-oriented system and the service-oriented system. From the founding of new China to the end of the $20^{\text {th }}$ century, the main task of teacher training in primary and secondary schools is the academic compensation education in the forms of correspondence university, evening university, off-the-job training. During this period, the teacher training is mainly controlled by the national macro policy and is an absolute planned system. With the China's economic transformation in the new century, education is also facing the transformation to meet the needs of society development. Teachers are the backbone of the transformation and development of education. The development and transformation of education ideas is inevitable, which is followed by the reform of teacher training system, the establishment of teacher training in rotation system and plans, and the huge increase in non-academic education programme of teacher training.

With the continuous development of China's market economy and promotion of education industrialization, the requirement of individualization in teacher development is increasing, and the demand of marketization and individuation of teacher training is increasingly urgent. The market-oriented education and training organizations begin to enter into the field of teacher training. However, these institutions only passively undertake the teacher training projects of government departments. It is the government who has the suppliers and the control over teacher training, while the market has no real rights. Therefore, this situation only introduces the market mechanism rather than realizing the marketization of teacher training services, and teacher training is not yet a social 
commodity at the level of complete marketization. This kind of training system cannot satisfy teachers' professional development nor can solve their problems in professional and career development. Hence, it is necessary to change the current lagging training system, establish the teacher training system that fits the development of teachers and the national conditions, and promote the teacher training to a market-oriented and service-oriented system.

\subsection{Environment Empowerment: The Conservative Teacher Training Culture}

The environment empowerment means to create a favorable cultural atmosphere and developmental environment for relevant groups and organizations. It is an effective resource that can be utilized and is of creativeness and inspirations. In terms of teacher training, the key point of environment empowerment is to create a healthy environment for the professional development. Under the influence of the planned teacher training system, teacher training is regarded as a compulsory command of the country, that is the participation in the training is a kind of management service and political task. In this case schools often neglect the construction of teachers' training cultural atmosphere and are short of the support for training culture, which leads to a lack of enthusiasm and initiative among primary and secondary school teachers. Therefore, it is difficult for them to achieve the ideal training by the passive participation.

In reality, the emphasis on teacher training in primary and secondary schools is mostly the requirements of administrative indicators, in other words a utilitarian goal. There is no cultural gene for the healthy teacher training and professional development fundamentally. Teacher training has become a "political task", which is contrary to not only the policy pursuit of teachers' professional development but the requirement of learning and professional teachers needed by the education development in the new era. The basic reason is that China's teacher training is still at the level of national administrative advocacy where there is not a fully realized marketization of teacher training, and thus no effective relationship between supply and demand. Besides, the social culture of teacher training and professional development is also absent and the cultural environment still keeps "scatted" without being internalized into the spirit of teachers. Consequently, shaping the teacher training culture is currently the core of environment empowerment and the necessity of promoting the popularization, full coverage, individuation and initiative of teacher training.

\subsection{Internal Enhancement: The Single Construction of Teacher Training Resources}

The internal enhancement emphasizes the improvement of the strength and ability of "internal initiative". As for teacher training, the internal enhancement is mainly the construction of teacher training resources, which is the core stimulate for teachers' participating in training. The construction of training resources should meet the needs of teachers' professional and career development, 
solve the problems in teachers' development, and develop along with the changing needs. At present, there are many problems in the resource construction of teacher training in China, such as the disconnection between training resources and demands, the disconnection between aged resources and practical issues, training teachers' lacking front-line practical experience, and the lack of systematicness in resource construction. In short, the mechanized training thought and resource construction in the old industrial age could no longer meet the individualized and diversified needs of teachers' development in the "Internet+" era.

With the coming "Internet+" era, new educational thoughts and educational issues have changed constantly, which poses more serious challenges to the development of teachers. The creative thinking is therefore needed to solve brand-new and individualized educational problems (Huang Yueling, Li Peng, and Zhu Dequan, 2017) [8]. Technologies like the big data and cloud computing find extensive application in education, which calls for teachers' training to keep pace with the times and provides technical supports for the diversified construction of teacher training resources. The construction of resources not only originated from the trainer but also the learners. Learners' participation and the rich resources presentation both promote the individualized needs of teachers' development. So, the alternation of old resource construction models and the improvement of the inner attraction of teacher training are the main aspects of the internal enhancement of teacher training.

\subsection{External Enhancement: The Scattered Teacher Training Standard System}

The external enhancement emphasizes the promoting effect of external forces in the process of ability enhancement, which advocates to activate the subject through external forces and to achieve the purpose of continuous enhancement through the continuous circulation and construction of the interaction between object and subject. In the training of primary and secondary school teachers, the establishment of a systematic assessment system and a quality standard system of teacher training are important measures to improve the quality and the effectiveness of teacher training services.

In the current teacher training in China, there is no systematic quality standard of teacher training, and the assessment system of teacher training tends to be rigid, not truly reflecting the training quality. The marketization in the reform of teacher training system in particular has a tendency to cause conflicts between economic benefits and social benefits. Only by the strict quality supervision can the training quality be guaranteed. Therefore, the marketization of teacher training system badly needs an assessment system with multiple subjects engaged and clear standards in order to form the performance feedback system of teacher training, select training resources and services with high qualities and eliminate the aged and old ones, and finally lead to a constant improvement of the teacher training quality on the whole. The nation must establish professional assessment 
institutions and advisory committees of experts for teacher training, promote the research on quality standards of teacher training, attract high-quality elements of teacher training services, improve the system of teacher training services, and eventually provide an all-round support for the improvement and optimization of national teacher training service system.

\section{Enlightenment from the Empowerment Model of Teacher Training in Singapore}

\subsection{Policy Empowerment: Teacher Training with the Long-Term Planning and Systematic Orientation}

The policy empowerment is the foundation of sustainable development, and policy supports with the advancing concept, precise orientation, long-term planning and sustainable system is the inexhaustible power to promote the sustainable development of teacher training. Recent years have witnessed a vigorous development of teacher training in China because of the published policies. All kinds of teacher training platforms, projects and bases provide supports and guarantees for teachers' professional development. However, there are many problems to be solved behind the prosperity. As mentioned in previous sections, primary and secondary school teachers' training in China started late, and the state-dominated teacher training has been unable to meet the individualized and diversified needs of primary and secondary school teachers in the "Internet+" era. Besides, the orientation of teacher training in the country tends to focus on short-term development goals. These issues all hinder the sustainable development of teacher training.

In terms of policy empowerment, based on the realities, teachers' training in primary and secondary schools should firstly make a scientific and long-term plan instead of the current "fragmented and short-term" one. In addition, it should focus on the long-term professional plan and reform and development of national foundation education, and make it clear the long-term position of teacher training in the education development. Finally, it should meet the individualized development needs of teachers.

\subsection{System Empowerment: Establishing the New State-Dominated and Market-Operated Teacher Training System}

The system empowerment is the key to optimize teacher training and improve the quality of training. The dominant power of teacher training changes with the practical needs of Singapore. Accordingly, Singapore has established a teacher training system dominated by the National Institute of Education and also decentralized in which the NIE leads the promotion of teachers' academic degrees and the school leads their short-term in-job training. At present, the state-dominated "plan-oriented" teacher training system has been unable to meet the personalized and diversified needs of teacher training. In the "Internet + " era, the optimization of teacher training system in Chinese primary and secondary 
schools must satisfy the individualized and diversified demand of teacher development.

The training for primary and secondary school teachers should establish a state-dominated and market-operated system on the base of Chinese education system. The country shall lead to ensure the general direction of teacher training and give full play to the advantages of marketization in the meantime in order to overcome the defects of planned teacher training system, push forward the marketization of training services, and ultimately improve the quality of training services. During this process, the country, society and school should break through multi-level institutional barriers and constraints and strive to build a new system of teacher training that is state-led and truly market-oriented, so as to provide professional, efficient and personalized services for teachers' development and satisfy the individualized needs.

\subsection{Environment Empowerment: Shaping the Cultural Atmosphere of Teachers' Active Development}

By analyzing the shaping of Singapore's teacher training culture and the existing problems in China, the empowerment of teacher training environment lies in the formation of a training culture in which teachers actively participate through improving policies and institutional mechanisms. It also lies in shaping teacher training culture, attaching importance to teacher training by the government, society and school, and activating teachers' enthusiasm for active learning. The shaping of training environment includes both the social environment in which social resources participate in teacher training and the cultural environment in which educational development genes are internalized into teachers' development.

As a result, China should focus on building a healthy competition mechanism for the market-participating teacher training in the process of environmental shaping, in order to ensure that training organizations can provide high-quality services for teacher development and meet the personalized needs of learning. With respect to the cultural shaping, training ideas are the core that determines the direction of teacher development. As for the teacher training there is an urgent need to change the vulgar ideas of "administrativization" and "credit-gaining" in the past, and to form the concept of "the basic literacy of teachers". The active learning of teachers is a kind of culture, a basic literacy that primary and secondary school teachers should have, a kind of comprehensive and systematic education integrated with professional development, and also an internalized cultural gene.

\subsection{Internal Enhancement: Establishing the "Curriculum + Resources" Coordinated Development of Teacher Training Resources}

As for teacher training in primary and secondary school teachers, the internal enhancement mainly focuses on promoting the inner driving forces of "Teachers 
+ Courses" in the construction of curriculum system and the faculty team. It also emphasizes to form curriculum resources based on technologies like big data, cloud computing and other information technologies and learners-engaged rich contents to meet the personalized needs of teacher development.

The inner driving forces aim to solve the problems of separation and disconnection between teacher training courses and teacher development and teaching practices. By exploring the mechanism of an effective integration of these two, to realize the deep integration of teacher training and professional development, which further improves the initiative of teachers' participation and establishes the quality of their active learning. With respect to the teaching faculty, it mainly concerns the optimization of the teaching staff, the perfection of training system with high-quality teachers by establishing teacher training resources coordinated by famous teachers and teaching experts, and the improvement of the teacher and teaching level. The fact that whether there are high quality teacher training resources or not is the key to test the ability of teachers' training and basic ability in our teacher training service system (Li Jinyu \& Shi Junlong, 2012) [7]. The cultivation of high-quality teacher training resources is to promote the systematic development of excellent researchers and front-line teachers, building a collaborative innovation of teacher training resources, and to develop individualized curriculum resources from the teaching practices and professional development of primary and secondary school teachers.

\subsection{External Enhancement: Improving the Systematization and Scientization of Teacher Training Institutions and Training Performance Assessments}

As discussed earlier, promoting the scientization of teacher training institutions and training effects assessment system is significant in the external enhancement. The establishment of scientific assessment system from the perspective of educational development laws and policies is an "invisible hand" ensuring the virtuous cycle of teacher training ecosystem. The interest-related government, training institutions, schools and teachers should all participate to form a comprehensive, all-round, scientific and dynamic assessment system.

The government, as the dominant power of teacher training, has the responsibility to establish a high-quality identification and selection mechanism and to set market-oriented access standards and elimination mechanisms for teacher training institutions. Primary and secondary schools and teachers involved in the training as the beneficiaries, should evaluate the training effects. It is also necessary to insist on the combination of process assessment and final assessment for teacher training, and so as to promote the development of teacher training in a dynamic way. In a word, the government should make the policy of teacher training quality assessment system, clarify the responsibilities, evaluation standards and reward and punishment mechanisms of all interest-related parties, and further ensure the sustainable and healthy development of teacher training. 


\section{Conclusion}

The development of Singapore education has trained a large number of high-quality talents for promoting the national economy; the policy and model of teacher training policies play an important role in the whole education system. Singapore's teacher training policy owns a clear positioning and systemic content, which finally formed a teacher training model to adapt to Singapore's national conditions. The kind of policy not only has established a state-led and decentralized teacher training system to promote the shaping of teacher training culture, but also has constructed diversified and personalized curriculum resources and platforms; in addition, it has set up a "training to Promotion" performance feedback system, etc. Comparing with Singapore's successful teacher training model, the training model of primary and secondary school teachers in China should focus on policy empowerment, institutional empowerment, environmental empowerment, internal and external empowerment, etc. Specifically, it is necessary to create a training model of primary and secondary school teachers which is suitable for Chinese national conditions through long-term planning and scientific positioning, thereby constructing a new state-led and market-operated teacher training system, shaping a cultural atmosphere to encourage teachers to improve itself, and building up a teacher training resource with "course \& resource" collaborative developing, and eventually promoting the systematic and scientific evaluation of teacher training institutions and training effects.

\section{Conflicts of Interest}

The author declares no conflicts of interest regarding the publication of this paper.

\section{References}

[1] Kloos, B., Hill, J., Thomas, E., Wandersman, A., Elias, M.J. and Dalton, J.H. (2012) Community Psychology. Wadsworth, Belmont, 352-353.

[2] Zhu, H.X. and Liu, X.N. (2004) The Guarantee Systems for the Teacher Professional Development in Singapore. Teacher Education Research, No. 6, 70-74.

[3] Ministry of Education, Singapore (2011) New “Teach" Framework to Enhance the Quality of the Teaching Force.

http://www.moe.gov.sg/media/press/2011/03/new-teach-framework-to-enhance-qu ality-teaching-force.php

[4] Ministry of Education, Singapore (2014) Education Statistics Digest 2013. http://www.moe.gov.sg/education/education-statistics-digest/files/esd-2013.pdf

[5] Tan, S.K.S. and Wong, I.Y.F. (2011) Developing Quality Teachers for the Singapore School System: The Impact of the National Institute of Education and the Tripartite Relationship with the Ministry of Education and Schools. http://www.atee1.org/uploads/2011annualconferenceproceedings.pdf

[6] Fan, B. (2004) The Empowerment and Model Selection of Vulnerable Groups. Academic Research, No. 12, 40-44.

[7] Li, J. and Shi, J. (2012) Teacher Training Concept from Multi Perspectives. Journal 
of Northwest Normal University (Natural Science), No. 5, 83-89.

[8] Huang, Y., Li, P. and Zhu, D. (2017) Crowd Funding of Resources: A New Supplying Model for the Teacher-Training's Curriculum Courses in the "Internet+" Era. China Educational Technology, No. 1, 58-63. 